\title{
When the rich do (not) trust the (newly) rich: Experimental evidence on the effects of positive random shocks in the trust game
}

\author{
Hernan Bejarano $^{1,2}$ - Joris Gillet ${ }^{3}$ - Ismael Rodriguez-Lara $^{2,4}$ \\ ${ }^{1}$ Center of Economics Research and Teaching, Economics Division (CIDE) \\ ${ }^{2}$ Economic Science Institute (ESI), Chapman University \\ ${ }^{3}$ Department of Economics, Middlesex University London \\ ${ }^{4}$ Department of Economics, Universidad de Granada
}

December 10, 2020

\begin{abstract}
We study behavior in a trust game where first-movers initially have a higher endowment than second-movers but the occurrence of a positive random shock can eliminate this inequality by increasing the endowment of the second-mover before the decision of the first-mover. We find that second-movers return less (i.e., they are less trustworthy) when they have a lower endowment than first-movers, compared with the case in which first and second-movers have the same endowment. Second-movers who received the positive shock return more than those who did not; in fact, secondmovers who received the positive shock return more than second-movers who had the same endowment as the first-mover from the outset. First-movers do not seem to anticipate this behavior from second-movers. They send less to second-movers who benefited from a shock. These findings suggest that in addition to the distribution of the endowments the source of this distribution plays an important role in determining the levels of trust and trustworthiness. This, in turn, implies that current models of inequality aversion should be extended to accommodate for reference points if random positive shocks are possible in the trust game.
\end{abstract}

Keywords: Trust game, endowment heterogeneity, random shocks, luck, inequality aversion, reference-dependent utility, reference points.

JEL Codes: C91, D02, D03, D69. 


\section{Introduction}

Incomplete contracts are ubiquitous in economic interactions (Hackett 1993, Chen 2000, Anderhub et al. 2002). Because it is not always possible to specify contingent responses to unforeseen circumstances, trading relations are often characterized by informal agreements. As a result, trust and trustworthiness are key in promoting cooperation and exchange (Smith 1776, Arrow 1974, Guiso et al. 2004). Trust and trustworthiness are also essential factors at the macroeconomic level helping with the development of a society (Knack and Keefer 1997, Zak and Knack 2001, Algan \& Cahuc 2010, Bjørnskov 2012, Algan et al. 2016, Batrancea et al. 2019). Hence, understanding the factors that can affect the levels of trust and trustworthiness is of firstorder importance.

One element that is likely to affect the levels of trust and trustworthiness is the degree of heterogeneity between group members (Alesina \& La Ferrara 2000, 2002); in particular, whether or not people differ in their wealth. ${ }^{1}$ In this context, one particular feature that we believe to be particularly important concerns how the wealth of individuals is established. Milanovic (2015) and Frank (2016) conclude that (good) luck plays an essential role in determining economic success and income. Therefore, one may argue that positive random shocks that affect the wealth of individuals (e.g., winning the lottery, experiencing extraordinarily good weather conditions for the crops you are growing, finding an oil well on your property) are likely to shape the behavior of both those affected by the positive random shock (i.e., the lucky ones) as well as those interacting with them, by affecting attitudes and beliefs regarding reciprocity and prosocial behavior. This paper uses a laboratory experiment to study the levels of trust and trustworthiness when people differ in their wealth but the occurrence of a positive random shock can eliminate the existing inequality. Are relatively richer people more or less likely to trust other rich people than people with a smaller endowment? But also, what if a relatively poor person is lucky and experiences a random positive shock that increases her wealth? Will this change the level of trust exhibited by the rich people towards them compared with their behavior in situations where the others have the same wealth from the outset? These are the questions we seek to answer in the current paper.

We follow the procedures in Bejarano et al. $(2018,2020)$ by using a variation of the trust game in Berg et al. (1995) and consider the possibility that relatively richer first-movers - who start out with a higher endowment than the second-movers - behave differently depending on the level or

1 There is evidence that wealth inequalities have noteworthy consequences in a variety of settings, icnluding antisocial behavior (Fehr 2018, Gangadharan et al. 2019), happiness (Alesina et al. 2004, Oishi et al. 2011), and cooperation (Zelmer 2003, Tavoni et al. 2011, Hargreaves-Heap et al. 2016, Camera et al. 2020). 
the source of the inequality. ${ }^{2}$ In our setting, the occurrence of a positive random shock depends on the outcome of a die roll that can eliminate the wealth inequality for specific pairs of first- and second-movers by increasing the endowment of the second-mover before the decision of the firstmover. Our experimental design incorporates two additional treatments - one where first-movers have a higher endowment than the second-movers, the other where first- and second-movers have the same endowment - but where these distributions exist from the outset and positive random shocks are not possible. This allows us to decouple the effect of the distribution of wealth and the source of the distribution on the levels of trust and trustworthiness.

We use our experimental data to test a number of different behavioral predictions we posit using outcome-based models. ${ }^{3}$ Models of inequality aversion, for instance, predict that second-movers will return less when they are relatively poorer than first-movers but traditional theory (Fehr \& Schmidt 1999, Bolton \& Ockenfels 2000) remains silent on the potential influence of the source of the inequality. In this regard, extending the model to reference-dependent utility (Kôszegi \& Rabin 2006, 2007, 2009) would predict second-movers to return more when they experiemce a positive random shock, compared with a setting in which second-movers start out with the same endowment as first-movers. As for the level of trust, an altruistic first-mover who wants to reduce the inequality is expected send more to a poorer second-mover than to a rich second-mover. Models of inequality-aversion therefore predict that exhibited trust of altruistic first-movers is lower when the endowment of the second-mover is higher. However, these models do not predict any difference in the behavior of first-movers towards "originally rich" second-movers (who were given the same endowment as the first-mover from the outset) and "newly rich" second-movers (who started out poor but experienced a positive random shock). Assuming that first-movers can anticipate that the occurrence of the positive random shock will lead to an increase in the utility of second-movers and that this affects their expectations of the level of trustworthiness we show that first-movers may behave differently in these two settings if we incorporate the idea of reference points and reference-dependent utility into the model. ${ }^{4}$

\footnotetext{
${ }^{2}$ In the trust game, first-movers decide the amount they want to send (if any) to second-movers. Any amount sent is multiplied by the experimenter by a given factor before the second-mover decides the amount to return (if any). Under the assumption of selfish preferences, the sub-game perfect equilibrium is that second-movers will return nothing to the first-movers, and consistently first-movers will not send any positive amount to second-movers. The behavior of first-mover has been usually identified in the literature as the level of trust, whereas how much the second mover returns is usually interpreted as the level of trustworthiness.

${ }^{3}$ Expectations about others' behavior and intentions are also important to determine behavior (McCabe et al. 2003, Chaudhuri \& Gangadharan 2007, Falk et al. 2008, Houser et al. 2008, Johansson-Stenman et al. 2013, Cox et al. 2016). For theoretical models that incorporate the role of beliefs and intentions see, among others, Rabin (1993), Dufwenberg \& Kirchsteiger (2004) and Cox et al. (2007).

4 In fact, first-movers can send more or less to (lucky) second-movers, depending on their beliefs regarding the reciprocal behavior of second-movers. We discuss in detail our theoretical predictions in Section 2.
} 
Our results provide evidence that people care about the source of inequality in the trust game, suggesting that reference-dependent preferences can help explain the behavior of first and secondmovers. We find that second-movers who experience a positive shock that increases their endowment return a higher share of the surplus that is generated by the action of the first-mover than second-movers that were initially given the same endowment as first-movers. Newly rich or lucky second-movers are therefore more trustworthy than those second-movers who are originally rich. First-movers do not seem to anticipate this behavior from second-movers; in fact, we find that first-movers send less to second-movers who experience a positive random shock, compared to what they send to second-movers that have the equal endowment from the outset. This provides evidence that rich first-movers trust "newly" rich second-movers less than they do those that are "originally" rich.

To our knowledge, our experiment is the first one that examines how the occurrence of positive random shocks can influence behavior in the trust game. The determinants of trust and trustworthiness have been extensively studied in laboratory experiments (Chaudhuri \& Gangadharan 2007, Eckel \& Wilson 2011, Johnson \& Mislin 2011, Cooper \& Kagel 2013, AlosFerrer \& Farolfi 2019). Most of the studies that examine how wealth inequalities influence trust and trustworthiness tend to vary the initial endowments of the first and/or the second-movers to examine how the behavior of people respond to differences in wealth (Anderson et al. 2006, Ciriolo 2007, Lei \& Vesely 2010, Xiao \& Bicchieri 2010, Smith 2011, Brülhart \& Usunier 2012, Hargreaves-Heap et al. 2013, Calabuig et al. 2016, Rodriguez-Lara 2018). Our findings align with this literature in that we show that inequality is important to explain the behavior in the trust game. However, we advance our understanding on the factors that influence trust and trustworthiness by showing that it is also important to account for the source of inequality; i.e., the way in which the distribution of wealth is determined.

The most closely related papers to ours are Bejarano et al. $(2018,2020)$, who study how negative random shocks can influence the level of trust and trustworthiness. In both papers, the first- and the second-mover start out with the same endowment, but the occurrence of negative random shock can decrease the endowment of one of the players. Bejarano et al. (2018) argue (and find support for the hypothesis) that random negative shocks that affect the endowment of secondmovers can lead to differences in the behavior of first-movers by making the inequality more salient; i.e., their data suggest that richer first-movers send less to relatively poor second-movers when their wealth level is the result of a negative random shock, compared with the case in which second-movers are relatively poor from the outset. Bejarano et al. (2020) focuses on the behavior of first-movers when a negative random shock can occur to them. They find that the possibility of the shock is also important to explain the behavior of first-movers, but the occurrence of the 
shock is not. In both papers, poor second-movers behave in the same manner towards rich secondmovers no matter whether or not the inequality was generated by a negative random shock. ${ }^{5}$ The current paper departs from these studies in that we consider a setting in which people already differ in their wealth, but the inequality can be eliminated if second-movers are lucky. In this way, we extend the findings of Bejarano et al. $(2018,2020)$ to examine how trust and trustworthiness respond to the occurrence of positive random shocks that eliminate wealth inequalities.

The remainder of the paper is organized as follows. We present our experimental design and derive our main hypotheses in Section 2. The results are presented in Section 3. Section 4 concludes.

\section{Experimental design and hypotheses}

\subsection{Experimental Design and procedures}

A total of 408 students with no previous experience in similar experiments were recruited to participate in 18 experimental sessions conducted at the ESI Chapman University between May 2014 and May $2018 .{ }^{6}$

At the beginning of each session, participants were welcomed and located in two different rooms (A and B). Once all of the students were seated, they were asked to read the instructions at their own pace (see Appendix A for the original instructions). The experimental material on the table of each participant contained an envelope with their initial endowment. Using the usual procedures for non-computerized trust game experiments, first-movers (in-room A) were asked to decide the amount of money they wanted to send (if anything) to their matched second-mover (in room B). The amount sent by each first-mover was placed in the envelope with the ID of their matched second-mover, and then tripled by the instructor in a separate room before being given to second-movers. Upon receiving these envelopes, second-movers were asked to decide the amount of money they wanted to return (if anything) to their matched first-mover.

\footnotetext{
${ }^{5}$ Bejarano et al. (2020) relate their findings to the occurrence of negative random shocks (e.g., natural disasters) in the field. Their contribution is to show that these shocks may not have a different effect on trust and trustworthiness than the inequality they generate. For studies that use field experiments to investigate how trust and trustworthiness respond to natural disasters see, among others, Cassar et al. (2007), Kanagaretnam et al. (2009), Fleming et al. (2014) or CaloBlanco et al. (2017).

${ }^{6} \mathrm{We}$ wanted to have unexperienced subjects, what delayed the data collection.
} 
The initial endowment of first-movers in all treatments was $21 \mathrm{E} \$ .^{7}$ Second-movers also received an initial endowment of $21 \mathrm{E} \$$ in our Baseline-Equal treatment. In Baseline-Unequal, secondmovers received $7 \mathrm{E} \$$. In the Bonus treatments, all second-movers started with an endowment of $7 \mathrm{E} \$$, but we rolled a die in front of the individual first-mover they were paired with before they made their decision. If the outcome of the die was even the second-mover's endowment was increased to $21 \mathrm{E}$ (Bonus-Equal). Otherwise, second-movers kept their initial endowment of 7 E\$ (Bonus-Unequal). To inform second-movers on the outcome of the die, we asked first movers to record this in an "Outcome card" that second-movers received from first-movers. When we distributed the envelopes to second-movers we asked them to show the outcome card to the instructor. We increased the initial endowment of the second-mover if the outcome of the die was even before making any decision about the amount to return. Table 1 summarizes our treatments. This includes information on the number of pairs in each treatment.

Table 1. Summary of treatment conditions

\begin{tabular}{|c|c|c|c|c|}
\hline \multirow[b]{2}{*}{ Treatment } & \multirow[b]{2}{*}{$\mathbf{N}$} & \multicolumn{2}{|c|}{ Initial endowments } & \\
\hline & & First-mover & Second-mover & \\
\hline Baseline-Equal & 53 & $21 \mathrm{E} \$$ & $21 \mathrm{E} \$$ & \\
\hline Baseline-Unequal & 52 & $21 \mathrm{E} \$$ & $7 \mathrm{E} \$$ & \\
\hline $\begin{array}{l}\text { Bonus-Equal } \\
\text { (Bonus) }\end{array}$ & 45 & $21 \mathrm{E} \$$ & $7 \mathrm{E} \$ \rightarrow 21 \mathrm{E} \$$ & $\begin{array}{l}\text { The outcome of the die was even, and } \\
14 \mathrm{E} \$ \text { were increased from the initial } \\
\text { endowment of the second-mover. }\end{array}$ \\
\hline $\begin{array}{l}\text { Bonus-Unequal } \\
\text { (No bonus) }\end{array}$ & 54 & $21 \mathrm{E} \$$ & $7 \mathrm{E} \$ \rightarrow 7 \mathrm{E} \$$ & $\begin{array}{l}\text { The outcome of the die was odd and } \\
\text { the second-mover kept her initial } \\
\text { endowment. }\end{array}$ \\
\hline
\end{tabular}

Note. $\mathrm{N}$ refers to the number of pairs in each treatment.

Baseline sessions lasted about 45 minutes, while bonus sessions lasted about an hour. The average earnings across all sessions were $\$ 20.80$, including a $\$ 7$ show-up fee.

\subsection{Power analysis}

We use G*Power 3 (Faul et al., 2007) to determine the sample size. Our primary interest is to test how rich first-movers behave towards equally rich second-movers, depending on whether or not a positive random shock has increased the endowment of second-movers. Our null hypothesis is, therefore, that there is no difference in the behavior of first-movers in the Baseline-Equal and the Bonus-Equal treatments. To obtain power of 0.80 with $\alpha=0.05$ to detect a medium effect of $d=$

\footnotetext{
${ }^{7}$ We use experimental Dollars (E\$) in our experiment. These were converted to actual dollars at the end of each session $(1 \mathrm{E} \$=\$ 0.50)$.
} 
0.5 , the projected sample size assuming a Laplace distribution is at least 86 pairs (i.e., 43 pairs in each treatment). As can be seen in Table 1, our study was carried out on 98 pairs for these treatments.

\subsection{Hypotheses}

We rely on outcome-based models to derive predictions regarding the behavior of the first and the second-movers. As we shall see, models of inequality aversion predict that first and secondmovers will behave differently depending on whether they have the same endowments (equal treatments) or fist-movers have a higher endowment than second-movers (unequal treatments). However, these models predict no difference in the behavior of first- and second-movers depending on how the distribution of endowments is determined. Subsequently, we augment the models of inequality-aversion to allow for the source of the distribution to play a role in the levels of trust and trustworthiness by incorporating the idea of reference-dependent utility.

Ley $e_{i}$ denote the level of endowment of player $i \in\{1,2\}$, where $i=1(i=2)$ stands for the first-mover (second-mover) and $e_{1} \geq e_{2}>0$. The first-mover decides the amount $X \in\left[0, e_{1}\right]$ to send to the second-mover, who has to choose the amount $Y$ to return. We define the return rate $y \in[0,1]$ as the share of the available funds that second-movers return to first-movers; i.e., $y=$ $Y / 3 X$. We denote $\pi_{i}$ the final payoffs of each of player $i \in\{1,2\}$, which is determined as follows:

(1) $\pi_{1}=e_{1}-X+Y=e_{1}+X(3 y-1)$

(2) $\pi_{2}=e_{2}+3 X-Y=e_{2}+3 X(1-y)$

Using backward induction, it is straightforward to show that the Nash equilibrium, if participants only cared about their own payoffs, is that first-movers will send nothing to second-movers. This is because second-movers have no incentive to return any positive amount. The fact that we do observe trust and trustworthiness highlights the role of pro-social behavior or other-regarding preferences in trust game experiments (Chaudhuri \& Gangadharan 2007, Eckel \& Wilson 2011, Johnson \& Mislin 2011, Cooper \& Kagel 2013, Alos-Ferrer \& Farolfi 2019).

One central idea in the literature of pro-social behavior concerns the possibility that subjects are inequality-averse and dislike payoff differences (Fehr \& Schmidt 1999, Bolton \& Ockenfels 2000). To allow for this possibility, we consider that players have the following utility function:

(3) $u_{i}=\pi_{i}-\alpha_{i}\left(\pi_{i}-\pi_{j}\right)^{2}$ 
where $\pi_{i}$ and $\pi_{j}$ are given by equations (1) and (2) and $\alpha_{i} \geq 0$ measures the extent to which player $i$ is concerned about the inequality, where $i, j \in\{1,2\}$ and $i \neq j$. If we solve for the optimal behavior of second-movers who are inequality-averse, we find that their optimal return rate will be given by:

(4) $y^{*}=\frac{2}{3}-\frac{1}{24 X \alpha_{2}}+\frac{e_{2}-e_{1}}{6 X}$

This equation shows that optimal return depends on the difference between $e_{2}-e_{1}$, thus secondmovers will return less when there is an inequality in favor of the first-mover (Xiao \& Bicchieri 2010, Hargreaves-Heap et al. 2013).

Prediction 1a. If second-movers are inequality averse, they will return less in the BaselineUnequal than in the Baseline-Equal treatment. Additionally, second-movers will return less in the Shock-Unequal than in the Shock-Equal treatment.

An obvious shortcoming of the previous model is that it assumes that what players care about is just the distribution of the endowments, not the way this distribution is generated. As a result, a simple model of inequality aversion would predict no differences in the behavior of secondmovers in the Bonus-Equal and the Baseline-Unequal treatments. We hypothesize that not only the initial distribution of endowments is important in determining the level of trust and trustworthiness, but that reference points will also shape behavior; e.g., when a positive random shock is realized. We build on the idea of reference-dependent utility in Kőszegi \& Rabin (2006, $2007,2009)$ to account for this possibility. In particular, we assume that second-movers use their initial endowment as a reference point $(r)$ and evaluate any gain in utility from this initial endowment using the function:

(5) $f\left(e_{2} \mid r\right)=e_{2}+\eta\left(e_{2}-r\right)$

where $e_{2} \geq r$ and $\eta \geq 0$ measures the extent to which the initial endowment of the second-mover affects her evaluation of the final endowment; i.e., $\eta=0$ when the initial endowment of the second-mover is not used as a reference point.

If we allow for reference-dependent utility, we find that the optimal return of second-movers who are inequality-averse and have reference-dependent utility will be the following: 
(6) $y^{*}=\frac{2}{3}-\frac{1}{24 X \alpha_{2}}+\frac{e_{2}-e_{1}}{6 X}+\frac{\eta\left(e_{2}-r\right)}{6 X}$

If reference-dependent utility is important for second-movers they will experience a gain in utility $\eta\left(e_{2}-r\right)>0$ when the positive random shock is realized and, as a consequence, they will be likely to reciprocate more in the Bonus-Equal treatment compared with the Baseline-Equal treatment. Second-movers will not behave any differently in the Bonus-Unequal treatment from the Baseline-Unequal treatment if the shock is not realized, given that $\eta\left(e_{2}-r\right)=0$ in this case. If the reference point does not matter for the behavior of second-movers then $\eta=0$ and equations (4) and (6) are the same.

Prediction 1b. If second-movers are inequality averse and have reference-dependent utility, they will return more in the Bonus-Equal than in the Baseline-Equal treatment. They will send similar amounts in the Bonus-Unequal and Baseline-Unequal treatments.

Next, we look at the behavior of first-movers. If first-movers are inequality averse, their behavior depends not only on their degree of inequality aversion $\left(\alpha_{1} \geq 0\right)$, but also on their beliefs about the inequality aversion of second-movers $\left(\alpha_{2} \geq 0\right)$. To derive testable predictions, we consider two different possibilities. First, we assume that first-movers are motivated by altruism. Second, we consider the possibility of self-interested first-movers who expect reciprocal behavior from second-movers but try to maximize their own payoff. ${ }^{8}$

Our idea of altruism follows from assuming that first-movers do not expect any reciprocal behavior form second-movers, thus first-movers behave so as to reduce the existing inequalities (Brülhart \& Usunier, 2012)

Prediction 2a. If first-movers are altruistic, they will send more in the Baseline-Unequal than in the Baseline-Equal treatment. Additionally, first-movers will send more in the Shock-Unequal than in the Shock-Equal treatment.

Because second-movers may behave differently depending on whether or not they have referencedependent utility, there may be a difference in the behavior of altruistic first-movers depending on whether or not they anticipate that second-movers will gain utility when a positive random shock is realized. If altruistic first-movers anticipate the gain in utility for second-movers when

\footnotetext{
8 Appendix $\mathrm{C}$ derives the predictions for the case in which first-movers are inequality averse and expect for secondmovers to be inequality averse. We show that the amount sent by first-movers is decreasing in the degree of inequality aversion of second-movers, $\alpha_{2}$.
} 
they experience a positive random shock, we expect them to send less to second-movers who received a positive shock than to second-movers who are initially given the same endowment as first-movers. This, in turn, implies that we can predict the following behavior from first-movers:

Prediction 2b. If first-movers are altruistic and believe that second-movers will obtain extra utility when the random shock is realized, first-movers will send more in the Baseline-Equal than in the Bonus-Equal treatment.

A second possibility is that first-movers anticipate that second-movers are inequality averse but first-movers behave in a self-interested manner trying to maximize their expected payoff (Smith, 2011). Under this assumption, first-movers will send more when they expect to receive more from second-movers. As in the case of altruistic first-movers, we expect differences in the behavior of self-interested first-movers depending on whether or not they anticipate that second-movers will gain in utility after the occurrence of the positive random shock. If first-movers are self-interested and expect no gain in utility, the behavior of first-movers will be the same in the Bonus-Equal and the Shock-Equal treatment. If they expect the gain in utility, first-movers anticipate that second-movers will be more likely to reciprocate after the occurrence of the positive random shock, thus first-movers will send more in the Bonus-Equal than in the Baseline-Equal treatment.

Prediction 3a. If first-movers are self-interested and anticipate that second-movers are inequality averse, they will send more in the Baseline-Equal than in the Baseline-Unequal treatment. Additionally, first-movers will send more in the Shock-Equal than in the Shock-Unequal treatment.

Prediction 3b. If first-movers are self-interested and anticipate that second-movers are inequality averse and use their initial endowment as a reference point, first-movers will send more in the Bonus-Equal than the Baseline-Equal treatment.

Overall, our predictions imply that models of inequality aversion can be used to rationalize differences in the behavior of first and second-movers between the equal and unequal treatments (Predictions 1a, 2a, 3a). However, these models cannot be reconciled with the data if we observe differences in behavior of first- and second-movers between the Baseline-Equal and the BonusEqual treatments, which could be explained incorporating the idea of reference-dependent utility (Predictions 1b, 2b, 3b). The comparison between predictions $2 \mathrm{a}$ and $3 \mathrm{a}$ and between $2 \mathrm{~b}$ and $3 \mathrm{~b}$ will shed light on whether the driving force for the first-movers' behavior is altruism or strategic. 


\section{Results}

We start by considering the behavior of second-movers by looking at the share of the available funds returned by second-movers; i.e., the return ratio. The left-hand-side panel of Figure 1 displays the average return ratio where first and second-movers have the same endowments (Equal treatments). The right-hand-side panel of Figure 1 displays the average return ratio in treatments where first-movers have a higher endowment than second-movers (Unequal treatments). The descriptive statistics and the distributions of the return ratio are presented in Appendix B. ${ }^{9}$

Figure 1. Proportion returned by second-movers
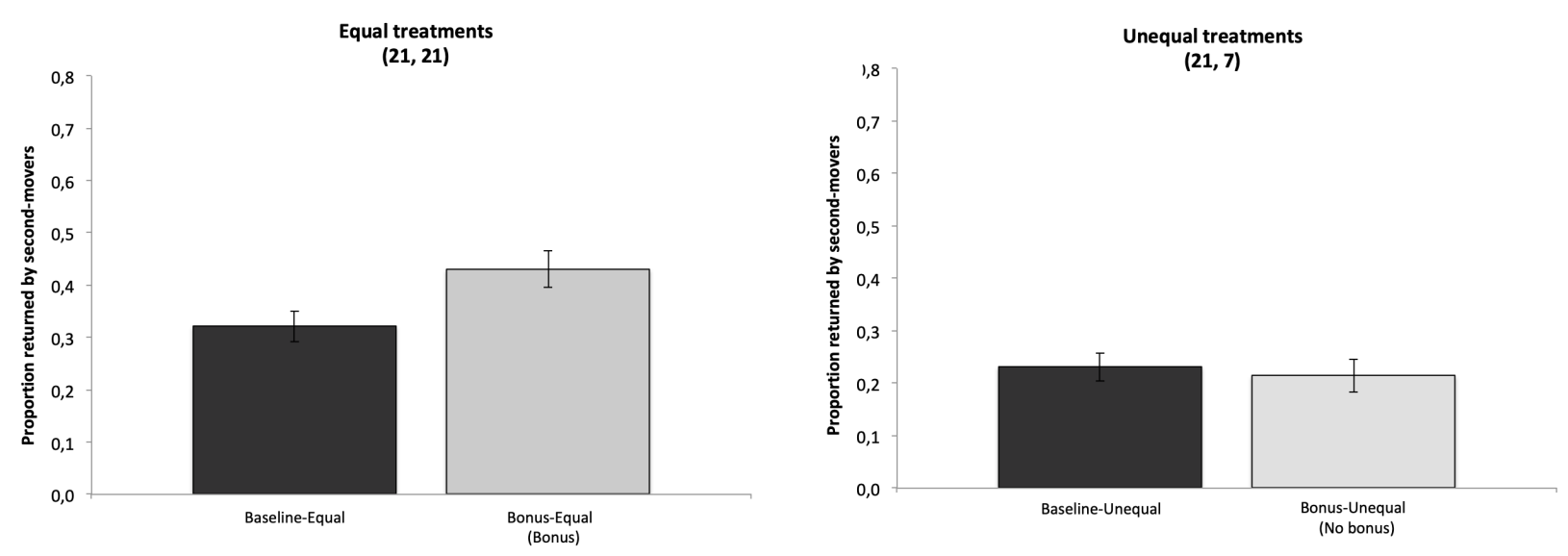

Note: Error bars reflect standard errors of the mean.

We perform non-parametric analyses to compare the behavior of second-movers across treatments using the Mann-Whitney test and the robust rank-order test (Fligner \& Pollicello 1981, Feltovich 2003). Table 1 summarizes the results.

Table 1. Non-parametric analysis for the share returned by second-movers

Mann-Whitney test Robust rank-order test

\begin{tabular}{lcc}
\hline Baseline-Equal $v s$ Baseline-Unequal & $2.189 * *$ & $2.249 * *$ \\
Bonus-Equal $v s$ Bonus-Unequal & $4.349 * *$ & $5.116 * *$ \\
Baseline-Equal $v s$ Bonus-Equal & $1.985 * *$ & $2.029 * *$ \\
Baseline-Unequal $v s$ Bonus-Unequal & 0.659 & 0.649 \\
\hline
\end{tabular}

\footnotetext{
${ }^{9}$ This includes the correlation coefficient between the proportion of the funds returned by second-movers and the amount they received from first-movers in each of the treatments. This has been used as a measure of reciprocity in other articles (e.g., Berg et al. 1995, Chaudhuri \& Gangadharan 2007, Calabuig et al. 2016). Our results suggest that in the correlation coefficients are insignificant in the equal treatments $(\mathrm{p}>0.114)$, but these are positive and significant in the unequal treatments $(\mathrm{p}<0.001)$.
} 
Notes: We report the Z-scores for both tests. Significance at *** $1 \%$ level, ** 5\% level (for two-tailed analysis). The results are robust if we adjust for multiple comparisons using the Holm-Bonferroni correction or the procedure in List et al. (2019).

Our findings for second-movers are consistent with the hypothesis of inequality aversion leading to Prediction 1a. Second-movers return a lower proportion of the generated funds in the Unequal treatments (where they have a smaller endowment than the first-mover), compared with the Equal treatments (where they have the same endowment as the first-mover). ${ }^{10}$ This occurs both in the Baseline treatments where the inequality is initially given (Baseline-Equal vs Baseline-Unequal: $p<0.024)$ as well as in the Bonus treatments where the endowment of the second-mover is increased (Bonus-Equal vs Bonus-Unequal, $p<0.001$ ).

Result 1. Second-movers return less if there is inequality in favor of the first-mover. Secondmovers return less in the Baseline-Unequal than in the Baseline-Equal treatment. Second-movers also return less in the Bonus-Unequal than in the Bonus-Equal treatment.

With regards to our main research question the results for second-movers suggest that the occurrence of the random positive shock influences reciprocal behavior, as second-movers return significantly more when their endowment is increased in the Bonus-Equal treatment, compared with the Baseline-Equal treatment $(0.43$ vs 0.32$)$ ( $\mathrm{p}<0.047)$. Thus, we find support for our Prediction $1 \mathrm{~b}$ that the occurrence of the positive random shock will increase the level of trustworthiness.

Result 2. The positive random shock that increases their endowment - and eliminates the existing inequality - causes second-movers to return more in the Bonus-Equal than in the Baseline-Equal treatment.

Next, we investigate the behavior of first-movers by looking at the amount sent in each treatment. The main findings are presented in Figure 2 and Table 2.

\footnotetext{
${ }^{10}$ In fact, the results of the Wilcoxon signed-rank test suggest that first-movers do not retrieve (on average) what they send to second-movers in the Unequal treatments $(\mathrm{p}<0.002)$. For first-movers retrieve what they have invested if second-movers return at least one third of the available funds. This idea of reciprocity is used, among others, in Coleman (1990), Chaudhuri \& Gangadharan (2007), Ciriolo (2007) or Rodriguez-Lara (2018).
} 
Figure 2. Amount sent by first-mover
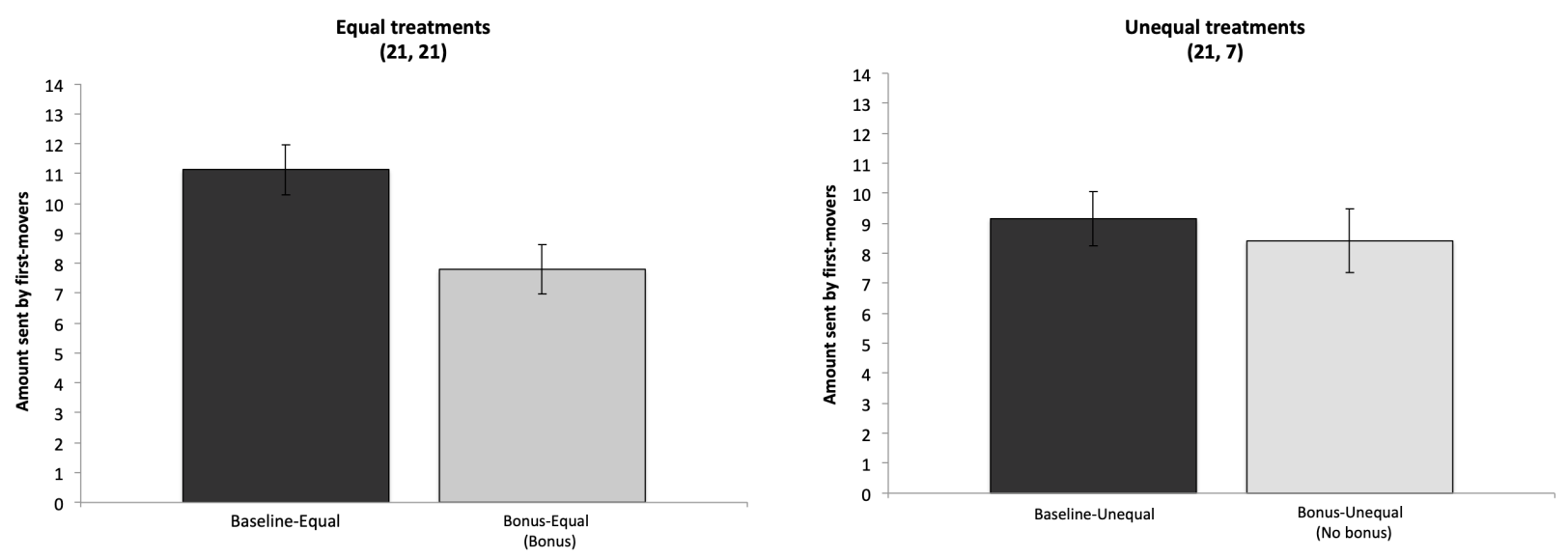

Note: Error bars reflect standard errors of the mean.

Table 2. Non-parametric analysis for the amount sent by first-movers

\begin{tabular}{lcc} 
& Mann-Whitney test & Robust rank-order test \\
\hline Baseline-Equal $v s$ Baseline-Unequal & $1.969 * *$ & $1.973 * *$ \\
Bonus-Equal $v s$ Bonus-Unequal & 0.141 & 0.138 \\
Baseline-Equal $v s$ Bonus-Equal & $3.129 * * *$ & $3.302 * * *$ \\
Baseline-Unequal $v s$ Bonus-Unequal & 1.066 & 1.042
\end{tabular}

Notes: We report the Z-scores for both tests. Significance at *** 1\% level, ** 5\% level (for two-tailed analysis). The results are robust if we adjust for multiple comparisons using the Holm-Bonferroni correction or the procedure in List et al. (2019).

When we compare the behavior in the Baseline-Equal and the Baseline-Unequal treatments, we find that first-movers send significantly more in the former treatment $(11.13 v s .9 .15)(p<0.049)$. There is no significant difference in the behavior of first-movers in the Bonus-Equal and the Bonus-Unequal treatments $(7.80 v s .8 .42)(p=0.888)$. These findings are more in line with Prediction 3a than Prediction 2a suggesting that self-interest plays a more prominent role in firstmover behavior than inequality aversion.

Result 3. First-movers send less in the Baseline-Unequal than in the Baseline-Equal treatment.

With regards to our main research question, we find that first-movers send significantly more in the Baseline-Equal than in the Bonus-Equal treatment (11.13 vs. 7.80) $(p=0.002)$ suggesting that the source of the endowment of second-movers matters for the behavior of first-movers.

Result 4. First-movers send less in the Shock-Equal than in the Baseline-Equal treatment. 
Result 4 seems to be more in line with Prediction $2 b$ than Prediction $3 b$, suggesting that in this context first-movers' behavior is mostly driven by considerations involving inequality aversion. This finding is at odds with Result 3 where we observed that self-interest plays a more prominent role than inequality aversion in the behavior of first-movers. It appears that the existence of the (possibility of the) shock changes the first movers' motivation.

\section{Conclusion}

This paper investigates whether (and how) different distributions of wealth influence the levels of trust and trustworthiness when we vary the source of the distribution. In addition to testing whether relatively rich people trust relatively poorer people more or less than they trust others with the same wealth as themselves, our primary interest is to test whether people exhibit the same trusting behavior towards "originally rich" and "newly rich" people. In the process of answering these questions we also study how the occurrence of the random positive shock affects the level of trustworthiness of those who are affected by the positive random shock.

We consider a variation of the trust game in which the occurrence of positive random shocks (i.e., the outcome of a die roll) can eliminate an existing inequality (in favor of the first-mover) by increasing the endowment of the second-mover. Our results suggest that first-movers $i$ ) trust second-movers with the same endowment as themselves more than relatively poorer secondmovers, but ii) trust second-movers who are lucky and obtain the same endowment as the firstmover after the occurrence of a positive random shock less than second-movers who had the same endowment from the outset. As for the level of trustworthiness, our results suggest that secondmovers $i$ ) are less trustworthy when they have a relatively lower endowment than first-movers, and ii) they are more trustworthy after having been lucky and experiencing a positive random shock that increases their endowment. These findings are consistent with previous evidence suggesting that the distribution of wealth is important in explaining behavior in the trust game (e.g., Ciriolo 2007, Lei \& Vesely 2010, Xiao \& Bicchieri 2010, Smith 2011, Brülhart \& Usunier 2012, Hargreaves-Heap et al. 2013, Calabuig et al. 2016). However, we add a new perspective to the existing literature by showing that it is also important to take the source of the distribution into account. In particular, our findings that first and second-movers behave differently depending on whether they originally have the same endowment or this is the result of a random positive shock calls for modeling the behavior in the trust game using models of inequality-aversion that incorporate the idea of reference-dependent utility if (positive) random shocks are possible. 
While our results for second-movers are consistent with theories involving inequality aversion and reference-dependent utility, the finding that first-movers send less to second-movers who have a lower endowment suggests that their behavior is not aimed at reducing the inequality but largely driven by self-interest; i.e., first-movers seem to anticipate that poorer second-movers will return less. With that in mind, the finding that first-movers send less to second-movers who have just received a positive random shock is somewhat puzzling. If first-mover behavior is driven by self-interest we would expect them to send more to those who have experienced a positive shock, since it seems quite likely that a second-mover who has just experienced an increase in their endowment will return a higher share of the available funds. Instead, we find the opposite in firstmovers. In our view, this result can only be explained by the assumption that first-movers hold self-serving beliefs regarding the behavior of second-movers.: First-movers are altruistic or selfinterested depending on the source of the inequality. If shocks are not possible first-movers expect second-movers to be inequality-averse. First-movers themselves are self-interested and send less to second-movers with a lower endowment. The occurrence of the positive random shock makes the issue of inequality-aversion more salient and makes the behavior of first-movers more influenced by notions of altruism. Seeing the second-mover experiencing a positive random shock makes the idea that second-movers do not deserve any more money more prominent. As a result, first-movers decide to send less to second-movers who have experienced a positive random shock. Along these lines, we believe that a fruitful area for future research would be to elicit the beliefs of first- and second-movers regarding the levels of trust and trustworthiness when random positive shocks are possible.

Our research opens up other interesting avenues for future research as well. For example, there is overwhelming evidence that people respond differently to inequalities that result from a random process and those that result from choices or merit, for instance in the context of redistribution (Konow 2000, Cherry et al. 2002, Alesina \& Angeletos 2005, Cappelen et al. 2007, 2013, Krawczyk 2010, Rodriguez-Lara \& Moreno-Garrido 2012, Durante et al. 2014, Mollerstrom et al. 2015, Deffains et al. 2016, Tinghög et al. 2017, Jimenez-Jimenez et al. 2018, Akbaş et al. 2019). Thus, it may be worth investigating how trust and trustworthiness are affected by random shocks when the initial endowments can be determined by luck or affected by performance in a real-effort task. A relevant paper within this line of research is Fehr et al. (2018). They explore how inequality affects the behavior in the trust game when participants receive different endowments depending on their performance in a real-effort task. Fehr et al. (2018) find that induced inequality affects the levels of trust and trustworthiness depending on the extent to which this is deemed fair by participants. They do not consider the possibility of random shocks. The 
current experiment suggests it may be worth considering a setting with real-effort and random shocks.

We believe that our results have policy implications as well. For example, our findings suggest that if a government decides to implement lump-sum transfers aimed at reducing inequality, these transfers could have a potential spillover effect increasing the level of reciprocity of those who receive them. On the other hand, these transfers could also diminish feelings of trust towards those who have received the transfers.

\section{Acknowledgments}

We are grateful to the staff and the graduate students at the Economic Science Institute (ESI) at Chapman University for their help in administering the sessions. This research was funded by the International Foundation of Research in Experimental Economics (IFREE) and the Research Facilitation Funding (RFF) at Middlesex University London. Ismael Rodriguez-Lara acknowledges financial support from the Ministerio de Innovación, Ciencia y Universidades (Spain) under the research project PGC2018-097875A-I00. The paper has benefited from suggestions provided by seminar and conference participants at the Universidad de Granada, 2018 ESA North America (Guatemala), 2019 Simposio de Análisis Económico (Alicante), and the 2020 ESA Global Online Around-the-Clock Meetings.

\section{References}

Akbaş, M., Ariely, D., and Yuksel, S. (2019). When is inequality fair? An experiment on the effect of procedural justice and agency. Journal of Economic Behavior \& Organization, 161, 114-127.

Alesina, A., and Angeletos, G. M. (2005). Fairness and redistribution. American Economic Review, 95(4), 960-980.

Alesina, A., and La Ferrara, E. (2000). Participation in heterogeneous communities. Quarterly Journal of Economics, 115(3), 847-904.

Alesina, A., and La Ferrara, E. (2002). Who trusts others? Journal of Public Economics, 85, 207-234.

Alesina, A., DiTella, R., and MacCulloch, R. (2004). Happiness and inequality: Are Europeans and Americans different? Journal of Public Economics, 88, 2009-2042.

Algan, Y. and Cahuc, P. (2010). Inherited trust and growth. American Economic Review, 100(5), 20602092.

Algan, Y., Cahuc, P., and Sangnier, M. (2016).Trust and the welfare state: The twin peaks curve. The Economic Journal 126.593, 861-883.

Alós-Ferrer, C., and Farolfi, F. (2019). Trust games and beyond. Frontiers in Neuroscience, 13, 887. 
Anderhub, V., Gächter, S., and Königstein, M. (2002). Efficient contracting and fair play in a simple principal-agent experiment. Experimental Economics, 5(1), 5-27.

Anderson, L., Mellor, J., and Milyo, J., (2006). Induced heterogeneity in trust experiments. Experimental Economics, 9, 223-235.

Arrow, K. (1974). The limits of organization. New York, Oxford University Press.

Batrancea, L., Nichita, A., Olsen, J., Kogler, C., Kirchler, E., Hoelzl, E., ... \& Schaffner, M. (2019). Trust and power as determinants of tax compliance across 44 nations. Journal of Economic Psychology, 74, 102191.

Bejarano, H., Gillet, J., and Rodriguez-Lara, I. (2018). Do negative random shocks affect trust and trustworthiness?. Southern Economic Journal, 85(2), 563-579.

Bejarano, H., Gillet, J., and Rodriguez-Lara, I. (2020). Trust and trustworthiness after negative random shocks. Working paper. https://doi.org/10.31235/osf.io/p4tw2

Berg, J., Dickhaut, J., and McCabe, K. (1995). Trust, reciprocity, and social history. Games and Economic Behavior, 10(1), 122-142.

Bjørnskov, C. (2012). How does social trust affect economic growth?. Southern Economic Journal, 78(4), 1346-1368.

Bolton, G. E., and Ockenfels, A. (2000). ERC: A theory of equity, reciprocity, and competition. American Economic Review, 90(1), 166-193.

Brülhart, M., and Usunier, J. C. (2012). Does the trust game measure trust? Economics Letters, 115(1), 2023.

Calabuig, V., Fatas, E., Olcina, G., and Rodriguez-Lara, I. (2016). Carry a big stick, or no stick at all: Punishment and endowment heterogeneity in the trust game. Journal of Economic Psychology, 57, 153171.

Calo-Blanco, A., Kovarik, J., Mengel, F., and Romero, J. G. (2017). Natural disasters and indicators of social cohesion. PloS One, 12(6), e0176885.

Camera, G., Deck, C., and Porter, D. (2020). Do economic inequalities affect long-run cooperation and prosperity?. Experimental Economics, 23(1), 53-83.

Cappelen, A. W., Hole, A. D., Sørensen, E. Ø., and Tungodden, B. (2007). The pluralism of fairness ideals: An experimental approach. American Economic Review, 97(3), 818-827.

Cappelen, A. W., Konow, J., Sørensen, E. Ø., and Tungodden, B. (2013). Just luck: An experimental study of risk taking and fairness. American Economic Review, 103(3), 1398-1413.

Cassar, A., Healy, A., and Von Kessler, C. (2017). Trust, risk, and time preferences after a natural disaster: experimental evidence from Thailand. World Development, 94, 90-105.

Chaudhuri, A., and Gangadharan, L. (2007). An experimental analysis of trust and trustworthiness. Southern Economic Journal, 73(4), 959-985.

Chen, Y. (2000). Promises, trust, and contracts. The Journal of Law, Economics, and Organization, 16(1), 209-232.

Cherry, T. L., Frykblom, P., and Shogren, J. F. (2002). Hardnose the dictator. American Economic Review, 92(4), 1218-1221. 
Ciriolo, E., (2007). Inequity aversion and trustees' reciprocity in the trust game. European Journal of Political Economy, 23, 1007-1024.

Coleman, J. (1990). Foundations of social theory. Cambridge, MA: Belknap Press.

Cooper, D., and Kagel, J., (2013). Other regarding preferences: A selective survey of experimental results. Forthcoming in J. H. Kagel, and A. Roth (Eds.), The handbook of experimental economics (Vol. 2). Princeton University Press.

Cox, J. C., Friedman, D. and Gjerstad, S. (2007). A tractable model of reciprocity and fairness. Games and Economic Behavior, 59, 17-45.

Cox, J. C., Kerschbamer, R., and Neururer, D. (2016). What is trustworthiness and what drives it? Games and Economic Behavior, 98, 197-218.

Deffains, B., Espinosa, R., and Thöni, C. (2016). Political self-serving bias and redistribution. Journal of Public Economics, 134, 67-74.

Dufwenberg, M., and Kirchsteiger, G. (2004). A theory of sequential reciprocity. Games and Economic Behavior, 47(2), 268-298.

Durante, R., Putterman, L., and Weele, J. (2014). Preferences for redistribution and perception of fairness: An experimental study. Journal of the European Economic Association, 12(4), 1059-1086.

Eckel, C. C., and Wilson, R. K. (2011). Trust and social exchange. In J. Druckman, D. Green, J. Kuklinski, and A. Lupia (Eds.). Handbook of Experimental Political Science, pp. 243-257. Boston: Cambridge University Press.

Falk, A., Fehr, E., and Fischbacher, U. (2008). Testing theories of fairness - Intentions matter. Games and Economic Behavior, 62(1), 287-303.

Faul, F., Erdfelder, E., Lang, A.-G., and Buchner, A. (2007). G*Power 3: A flexible statistical power analysis program for the social, behavioral, and biomedical sciences. Behavior Research Methods, 39(2), 175-191.

Fehr, D. (2018). Is increasing inequality harmful? Experimental evidence. Games and Economic Behavior, 107, 123-134.

Fehr, D., Rau, H., Trautmann, S. T., and Xu, Y. (2018). Inequality, Fairness, and Social Capital, mimeo.

Fehr, E., and Schmidt, K. M. (1999). A theory of fairness, competition, and cooperation. Quarterly Journal of Economics, 114, 817-868.

Feltovich, N. (2003). Nonparametric tests of differences in medians: comparison of the Wilcoxon-MannWhitney and robust rank-order tests. Experimental Economics, 6(3), 273-297.

Fleming, D. A., Chong, A., and Bejarano, H. D. (2014). Trust and reciprocity in the aftermath of natural disasters. Journal of Development Studies, 50(11), 1482-1493.

Fligner, M.A. and Pollicello, G.E. III. (1981). Robust Rank Procedures for the Behrens-Fisher Problem. Journal of the American Statistical Association. 76, 162-168.

Frank, R. H. (2016). Success and Luck: Good Fortune and the Myth of Meritocracy. Princeton University Press.

Gangadharan,L., Grossman, P. J., Molle, M. K., \& Vecci, J. (2019). Impact of social identity and inequality on antisocial behaviour. European Economic Review, 119, 199-215. 
Guiso, L., Sapienza, P., and Zingales, L. (2004). The role of social capital in financial development. American Economic Review, 94 (3), 526-556

Hackett, S. C. (1993). Incomplete contracting: a laboratory experimental analysis. Economic Inquiry, 31(2), 274-297.

Hargreaves-Heap, S. P, Tan, J. H. W., and Zizzo, D. J. (2013). Trust, inequality and the market. Theory and Decision 73, 311-333.

Hargreaves-Heap, S. P. H., Ramalingam, A., and Stoddard, B. V. (2016). Endowment inequality in public goods games: A re-examination. Economics Letters, 146, 4-7.

Houser, D., Xiao, E., McCabe, K., and Smith, V. (2008). When punishment fails: Research on sanctions, intentions and non-cooperation. Games and Economic Behavior, 62(2), 509-532.

Jimenez-Jimenez, N., Molis, E., and Solano-García, A. (2018). The effect of initial inequality on meritocracy: A voting experiment on tax redistribution. Journal of Economic Behavior \& Organization, forthcoming.

Johansson-Stenman, O., Mahmud, M., and Martinsson, P. (2013). Trust, trust games and stated trust: Evidence from rural Bangladesh. Journal of Economic Behavior \& Organization, 95, 286-298.

Johnson, N. D., and Mislin, A. A. (2011). Trust games: A meta-analysis. Journal of Economic Psychology, 32(5), 865-889.

Kanagaretnam, K., Mestelman, S., Nainar, K., and Shehata, M. (2009). The impact of social value orientation and risk attitudes on trust and reciprocity. Journal of Economic Psychology, 30(3), 368-380.

Knack, S., and Keefer, P., (1997). Does social capital have an economic payoff? A cross-country investigation. Quarterly Journal of Economics, 112, 1251-1288.

Konow, J. (2000). Fair shares: Accountability and cognitive dissonance in allocation decisions. American Economic Review, 90(4), 1072-1091.

Kőszegi, B., \& Rabin, M. (2006). A model of reference-dependent preferences. Quarterly Journal of Economics, 121(4), 1133-1165.

Kőszegi, B., \& Rabin, M. (2007). Reference-dependent risk attitudes. American Economic Review, 97(4), 1047-1073.

Kőszegi, B., \& Rabin, M. (2009). Reference-dependent consumption plans. American Economic Review, 99(3), 909-36.

Krawczyk, M. (2010). A glimpse through the veil of ignorance: Equality of opportunity and support for redistribution. Journal of Public Economics, 94(1-2), 131-141.

Lei, V., and Vesely, F. (2010). In-group versus out-group trust: the impact of income inequality. Southern Economic Journal, 76(4), 1049-1063.

List, J. A., Shaikh, A. M., and Xu, Y. (2019). Multiple hypothesis testing in experimental economics. Experimental Economics, 22(4), 773-793.

McCabe, K. A., Rigdon, M. L., Smith, V. L. (2003). Positive reciprocity and intentions in trust games. Journal of Economic Behavior \& Organization, 52(2), 267-275.

Milanovic, B. (2015). Global inequality of opportunity: How much of our income is determined by where we live? Review of Economics and Statistics, 97(2), 452-460. 
Mollerstrom, J., Reme, B. A., and Sørensen, E. Ø. (2015). Luck, choice and responsibility-An experimental study of fairness views. Journal of Public Economics, 131, 33-40.

Oishi, S., Kesebir, S., and Diener, E. (2011). Income inequality and happiness. Psychological Science, 22(9), 1095-1100.

Rabin, M. (1993). Incorporating fairness into game theory and economics. American Economic Review, 83(5), 1281-1302.

Rodriguez-Lara, I. (2018). No evidence of inequality aversion in the investment game. PloS One, 13(10), e0204392.

Rodriguez-Lara, I., and Moreno-Garrido, L. (2012). Self-interest and fairness: Self-serving choices of justice principles. Experimental Economics, 15(1), 158-175.

Smith, A. (1776). An Inquiry into the Nature and Causes of the Wealth of Nations. Eds: W. Strahan and T. Cadell, London.

Smith, A. (2011). Income inequality in the trust game. Economics Letters, 111(1), 54-56.

Smith, V. L., and Wilson, B. J. (2019). Humanomics: Moral sentiments and the wealth of nations for the twenty-first century. Cambridge University Press.

Tavoni, A., Dannenberg, A., Kallis, G., \& Löschel, A. (2011). Inequality, communication, and the avoidance of disastrous climate change in a public goods game. Proceedings of the National Academy of Sciences, 108(29), 11825-11829.

Tinghög, G., Andersson, D., and Västfjäll, D. (2017). Are Individuals Luck Egalitarians?-An experiment on the influence of brute and option luck on social preferences. Frontiers in Psychology, 8, 460.

Xiao, E., and Bicchieri, C. (2010). When equality trumps reciprocity. Journal of Economic Psychology, 31(3), 456-470.

Zak, P. J., and Knack, S. (2001). Trust and growth . The Economic Journal, 111(470), 295-321.

Zelmer, J. (2003). Linear public goods experiments: A meta-analysis. Experimental Economics, 6(3), 299310. 